Article

\title{
Anti- and De-Icing Behaviors of Superhydrophobic Fabrics
}

\author{
Yuyang Liu, Dong Song and Chang-Hwan Choi * \\ Department of Mechanical Engineering, Stevens Institute of Technology, Hoboken, NJ 07030, USA; \\ tcliuyy@gmail.com (Y.L.); dsong3@stevens.edu (D.S.) \\ * Correspondence: cchoi@stevens.edu; Tel.: +1-201-216-5579
}

Received: 2 May 2018; Accepted: 21 May 2018; Published: 23 May 2018

\begin{abstract}
This paper reports the application of superhydrophobic coatings on cotton fabrics and their functionalities for anti- and de-icing efficacy. Superhydrophobic cotton fabrics with different water-repellent properties have been achieved by decorating the surface of pristine cotton fibers with $\mathrm{ZnO}$ structures of varying sizes and shapes through an in situ solution growth process, followed by the treatment of the surface with low-surface-energy coating such as Teflon. The surface morphology of the treated cotton fabrics was characterized using scanning electron microscopy (SEM). The surface wettability of the treated fabrics was evaluated through the measurement of static contact angle (SCA), contact angle hysteresis (CAH), and sliding angle (SA) of a water droplet. The anti- and de-icing behaviors of the treated fabrics were evaluated through both static (sessile droplet) and dynamic (spraying) tests. The results show that the superhydrophobic fabric with a higher SCA and the lower CAH/SA has superior anti- and de-icing behaviors in both the static and dynamic conditions. Compared to hard substrates, the soft, flexible, and porous (air-permeable) superhydrophobic fabrics can lead to broader applicability of textile-based materials for the design and fabrication of antiand de-icing materials. Furthermore, the multi-scale surface structures of fabrics (fibers, yarns, and weaving constructions) combining with the hierarchical micro-nanostructures of the $\mathrm{ZnO}$ coating provides an ideal platform for anti-icing studies.
\end{abstract}

Keywords: anti-icing; de-icing; fabrics; nanostructures; superhydrophobic

\section{Introduction}

Superhydrophobic materials and surfaces [1-4] have attracted great interest because of their extreme water-repellent surface property for many potential applications including self-cleaning [5-7], hydrodynamic friction reduction [8-10], anti-icing [11-14], anticorrosion [15-18], biotechnology [19-21], thermal systems [22-25], and micro- and nanodevices [26-28]. In particular, previous works on the use of superhydrophobic surfaces as anti-icing coatings have demonstrated that superhydrophobic surfaces have the capability to reduce or even prevent the accumulation and formation of snow and ice on hard solid surfaces [11-14]. Aizenberg's team [13] designed nanostructured surfaces that could be used for anti-icing applications. Their experimental results show that highly ordered superhydrophobic materials can be designed to remain entirely ice-free down to circa -25 to $-30{ }^{\circ} \mathrm{C}$, due to their ability to repel impacting water before ice nucleation occurs. However, the limitations of the superhydrophobic surfaces on the anti-icing applications have also been reported recently. Due to the complexity of water property, frost nucleation within structured surfaces is hardly avoided considering the fact that evaporation accompanies the freezing process and change the surface behavior, which will even increase the adhesion force of ice on the roughened superhydrophobic surfaces [12,29]. Gao et al. indicated that the anti-icing competence of superhydrophobic surfaces depended not only on the superhydrophobicity but also the size of the 
surface roughness [11]. To prevent icing formation, nano-sized structures, smaller than the size of the critical nucleus of ice, has to be introduced on the superhydrophobic surfaces.

To enhance the hydrophobicity of a surface, the combination of the surface texturing and chemical modification has been widely applied based on the wetting theory of Cassie-Baxter model [30]. Recently, it has been demonstrated that by controlling the physical property of the substrate, surface flexibility for example, the superhydrophobicity can be significantly enhanced under dynamic conditions [31]. Even though many engineering and natural surfaces are flexible [32], the anti- and de-icing property of superhydrophobic structures on soft, flexible, and porous textile surfaces still remains unexplored. In this paper, we demonstrate the synthesis of superhydrophobic fabrics which are soft, flexible, and porous, and their anti- and de-icing properties under both static (Sessile drop) and dynamic (impacting supercooled droplet) conditions.

\section{Experimental Setup}

\subsection{Preparation of Cotton Fibers Decorated with $\mathrm{ZnO}$ Structures}

Cotton fibers decorated with $\mathrm{ZnO}$ structures were prepared by treating pristine cotton fabric with an in situ hydrothermal growth process. The details of this procedure are schematically shown in Figure 1. Cotton fabrics were kept in deionized water at $90{ }^{\circ} \mathrm{C}$ with stirring for $30 \mathrm{~min}$ to dissolve impurities. Then, the cotton fabric samples were rinsed with tap water for $2 \mathrm{~min}$ to remove the impurities and then dried at $120^{\circ} \mathrm{C}$ in a pre-heated oven for $30 \mathrm{~min}$. The cotton fabrics were cut into small pieces $(10 \mathrm{~cm} \times 20 \mathrm{~cm})$ and then the specimens were placed into a 1000-mL beaker containing bulk growth solution with equal molar amount of zinc nitrate hexahydrate (99\%) and hexamethylenetetramine (97\%). The bulk growth solution together with the cotton samples were heated to $90^{\circ} \mathrm{C}$ at the rate of $10^{\circ} \mathrm{C} / \mathrm{min}$ and then kept at $90^{\circ} \mathrm{C}$ for the growth of $\mathrm{ZnO}$ structures. Cotton fibers with four different surface structures were designed to achieve different surface wettabilities. The size and shape of $\mathrm{ZnO}$ structures decorated on the fiber surface were controlled by growth time and the addition of surfactant sodium dodecyl sulfate (SDS). Figure $1 \mathrm{~b}$ shows the schematic of the cotton fiber decorated with $\mathrm{ZnO}$ microparticles, where the growth time is limited to be short (10 min) with no use of surfactant. In comparison, Figure 1c,d show the schematic of the cotton fiber decorated with $\mathrm{ZnO}$ nanostructures. The longer growth time $(30 \mathrm{~min})$ with the use of surfactant is employed for the growth of $\mathrm{ZnO}$ nanowire structures on the surface of cotton fiber (Figure 1c). After the growth of the nanowire structures for the first layer, the samples were taken out from the reaction solution, rinsed with deionized water four times (by dipping the sample in $500 \mathrm{~mL}$ deionized water) to remove surface residuals. Then, the samples were put back to the reaction solution for the growth of nanoflower structures. Additional growth time $(60 \mathrm{~min})$ with the use of surfactant was employed for the growth of nanoflower structures on top of the nanowire structures (Figure 1d). The cotton fabric sample was taken out from the bulk solution after the modulated process time and condition. The samples were then rinsed with tap water and dried at $120^{\circ} \mathrm{C}$ for $30 \mathrm{~min}$. The $\mathrm{ZnO}$ structures grown on the cotton fibers were characterized with field-emission scanning electron microscope (FE-SEM, JEOL, Tokyo, Japan). 


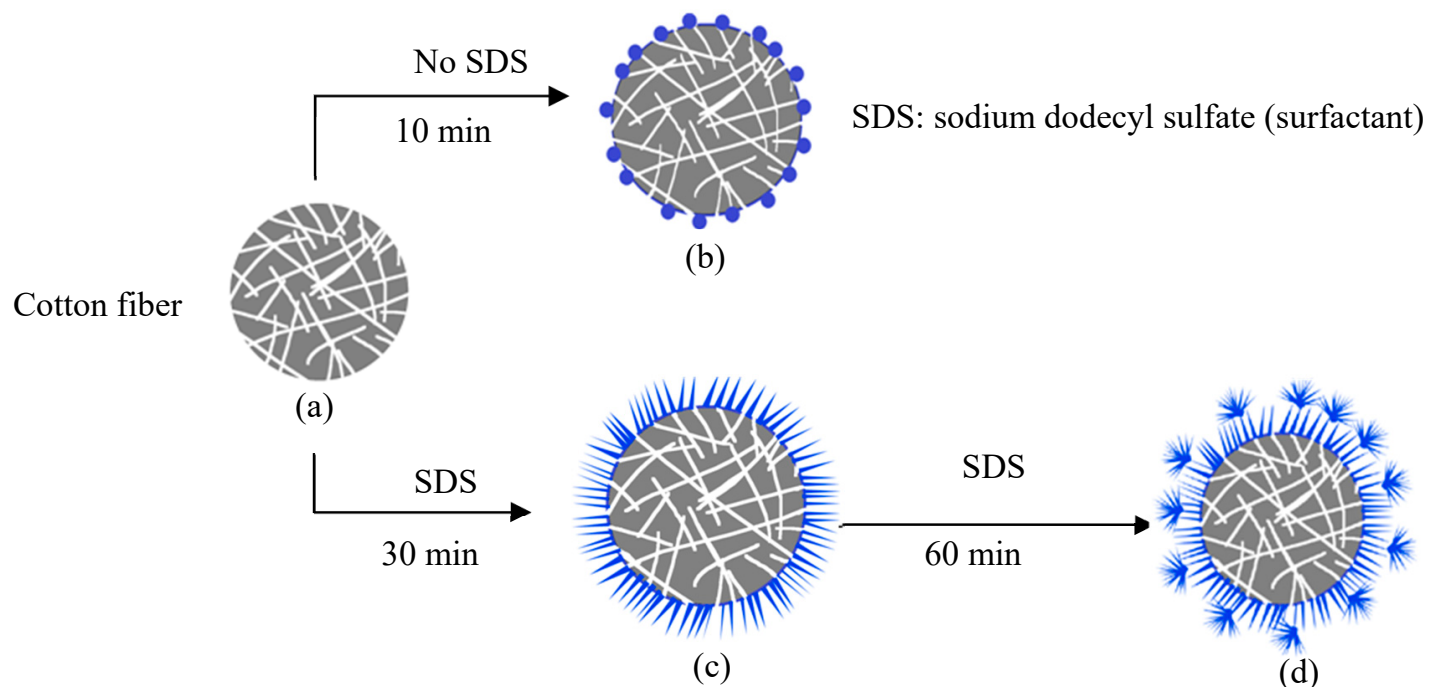

Figure 1. Decoration of cotton fibers with $\mathrm{ZnO}$ structures through an in situ solution growth process. (a) Pristine cotton fiber; (b) Cotton fiber coated with $\mathrm{ZnO}$ microparticles; (c) Cotton fiber coated with $\mathrm{ZnO}$ nanowire structures; (d) Cotton fiber coated with nanoflower-over-nanowire structures.

\subsection{Hydrophobic Coating of Cotton Fabric Samples with Teflon}

All the cotton samples were hydrophobized with Teflon coating by dipping the cotton samples in the solution of $0.1 \%$ Teflon AF 1600 [33] in FC-40 (3M ${ }^{\mathrm{TM}}$ Fluorinert ${ }^{\mathrm{TM}}$ Electronic Liquid) for 2 min and then dried at $120^{\circ} \mathrm{C}$ in a pre-heated oven for $30 \mathrm{~min}$ in an oven.

\subsection{Evaluation of Surface Wettability}

The surface wettability of the cotton fabric samples was evaluated by measuring the contact angle (CA), the contact angle hysteresis (CAH), and the sliding angle (SA) of a sessile droplet of water at room condition with a custom-made goniometer system. For the CA, static contact angle (SCA), advancing contact angle (ACA), and receding contact angle (RCA) were measured. The ACA and the RCA were measured during the sliding tests. The $\mathrm{CAH}$ was evaluated as the difference between the ACA and RCA.

\subsection{Evaluation of Anti-Icing and De-Icing Properties}

The anti-icing behavior of the cotton fabric samples was evaluated by both static and dynamic tests. In the static test, three water droplets (volume around $0.1 \mathrm{~mL}$ ) were first placed on the cotton fabric surfaces and then kept at $-18{ }^{\circ} \mathrm{C}$ in a biochemical freezer to allow icing. Several parallel experiments were conducted and the ice beads formed on the fabric surfaces were crushed with tweezers to check the fully frozen state. After the fully frozen state, the samples were placed on a $45^{\circ}$-slope plate and exposed to a room condition $\left(25^{\circ} \mathrm{C}\right.$ and $50 \%$ relative humidity (RH)) immediately to test subsequent de-icing behavior. In the dynamic test, a spraying test method was employed, based on AATCC (American Association of Textile Chemists and Colorists) Test Method 22-2005. The schematic of the instrument for the spraying test is shown in Figure 2. First, the fabric sample was placed on a $45^{\circ}$-slope plate. Then, $50 \mathrm{~mL}$ supercooled water was sprayed onto the fabric surfaces at a height of $15 \mathrm{~cm}$. The ice formation and mobility on the surfaces were measured. The supercooled water was prepared by pouring double distilled water into clean plastic bottles and then kept the bottles in the freezer at temperature of $-4{ }^{\circ} \mathrm{C}$ for $2-3 \mathrm{~h}$. The exact time for the formation of supercooled water depends on the temperature of the freezer. In order to ensure the formation of supercooled water, a control bottle containing tap water was also placed into the freezer at the same time. When the tap water freezes, it guarantees that the double distilled water is supercooled. The supercooled 
water bottles were kept intact until the spraying tests, because supercooled water can freeze easily when disturbed.

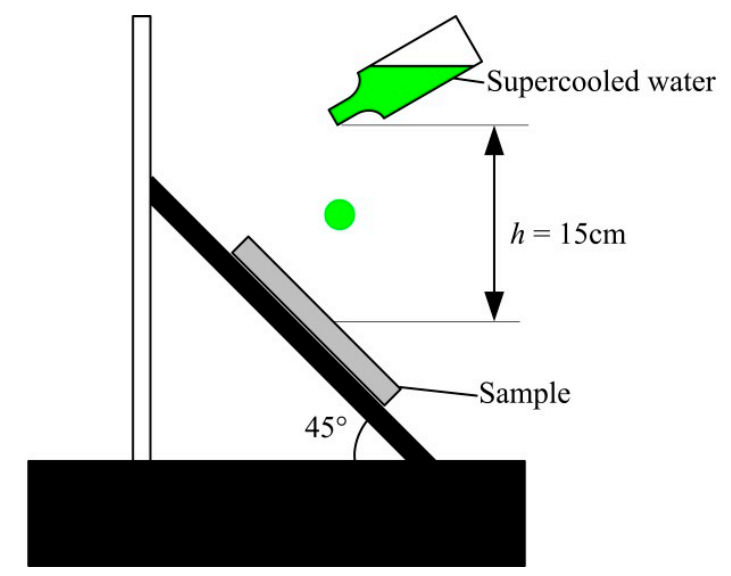

Figure 2. Schematic diagram of the dynamic spraying test.

\section{Results and Discussion}

\subsection{ZnO Surface Structures Grown on Cotton Fibers}

Figure 3 shows the SEM images of the cotton fibers prepared using the process described in Figure 1. The structures of the pure cotton fibers coated with Teflon is shown in Figure 3a, indicating that a cotton fiber has a relatively smooth surface and a characteristic diameter of $\sim 20 \mu \mathrm{m}$. Figure $3 \mathrm{~b}$ shows the Teflon-coated $\mathrm{ZnO}$ microstructures grown on the cotton fibers following the process shown in Figure 1b. In this case, there is a layer of secondary microstructures, distributed randomly and sparsely on the microfibers of cotton. The shapes of secondary microstructures are spherical and their sizes (diameters) range between 1 and $2 \mu \mathrm{m}$. The formation of the random microstructures results from the relatively poor control of crystallization in the pure aqueous solution without any precursor solution. In contrast, with the aid of surfactant such as SDS, ZnO with different shapes such as rod-like, wire-like, and spherical nanoparticles can be obtained by varying the amount of surfactant molecules, reaction time, and reaction temperatures [34-36]. Figure 3c shows the Teflon-coated $\mathrm{ZnO}$ nanostructures grown on the cotton fibers treated with the bulk growth solution containing $0.1 \%$ $\mathrm{SDS}$ for $30 \mathrm{~min}$ (following the process shown in Figure 1c). The secondary $\mathrm{ZnO}$ microstructures transformed to be nanowires (typical diameter of $\sim 200 \mathrm{~nm}$ ) which are now dense and fully covering on the cotton microfibers. The result demonstrates that the elongated growth time with the use of surfactant $(0.1 \%$ SDS $)$ allows the reduction of the size of $\mathrm{ZnO}$ particles and makes them have the shape of nanowire morphology and fully cover the surface. The origin of the morphology difference is due to the chemical interaction between the $\mathrm{ZnO}$ seed crystal and the ions produced by the ionization of the SDS [36,37]. The negatively charged SDS ions create micelles around the $\mathrm{ZnO}$ seeds during the reaction which causes the supplement of $\mathrm{Zn}^{2+}$ for $\mathrm{ZnO}$ seeds to be insufficient. As a result, the chemically activated lattice defects form on the surface and serve as nucleation sites of the growth of $\mathrm{ZnO}$ rods in random directions. If we extend the growth time to $60 \mathrm{~min}$ while keeping the concentration of surfactant (SDS) the same with the previous one as $0.1 \%$ (following the process shown in Figure 1d), the third layer of smaller nanowires forms on top of the secondary nanowires, resulting in a hierarchical morphology of nanoflower structures over the nanowires as clearly shown in Figure 3d. The diameter of the nanoflower morphology within the thirdly-grown layer is around 20-50 nm, having sharper tips and much smaller size than the first-grown nanowire structures. The results shown in Figure 3 illuminate that cotton fabrics decorated with the $\mathrm{ZnO}$ structures of various sizes and shapes can be conveniently achieved by using the in-situ hydrothermal growth process with the modulation of the growth time and the use of surfactant. The $\mathrm{ZnO}$ coating is reportedly durable to sustain the 
superhydrophobicity even when being immersed in a hydrochloric acid or sodium hydroxide solution for several hours [38-40].

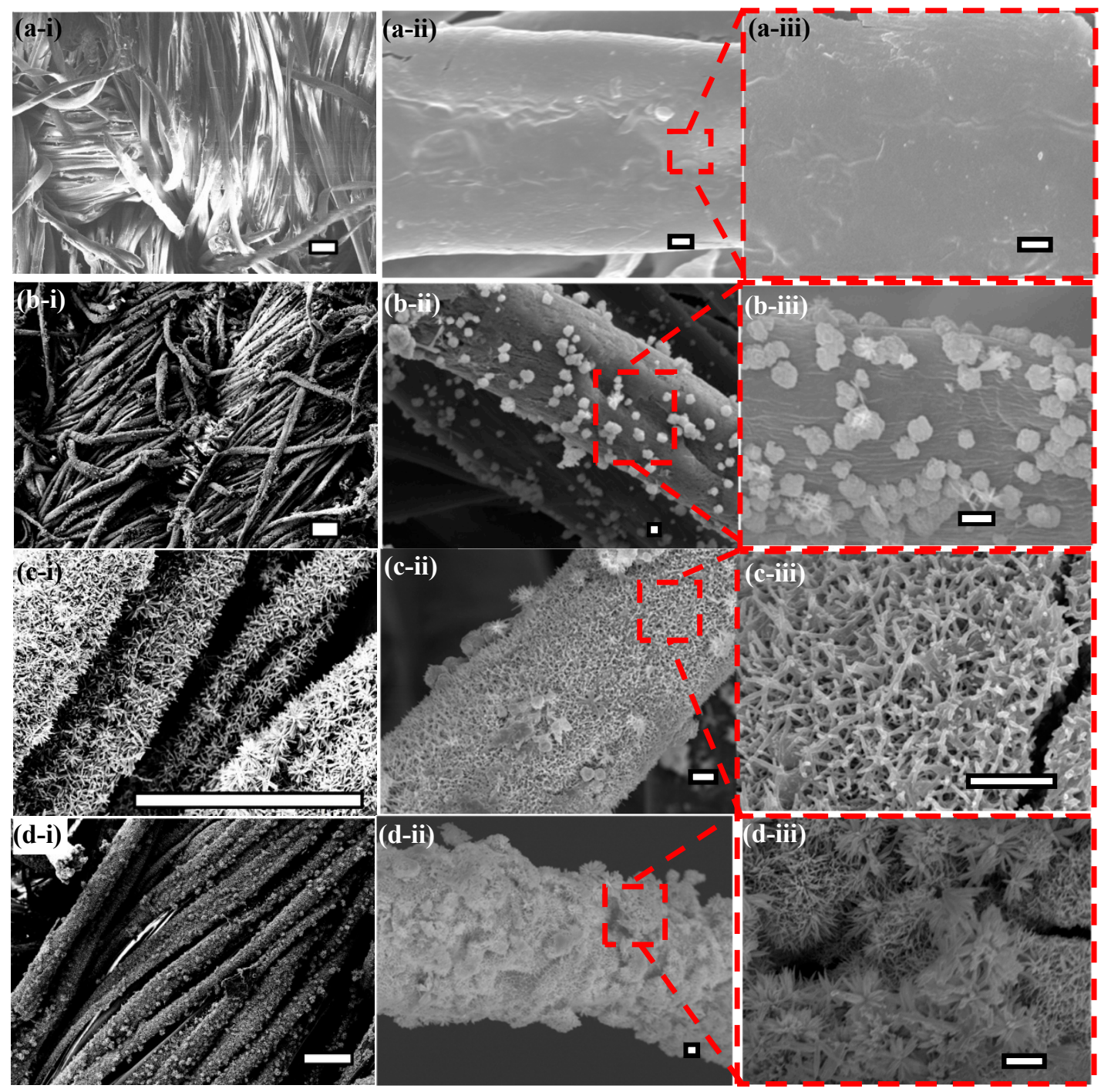

Figure 3. SEM images of cotton fibers decorated with different $\mathrm{ZnO}$ structures. (a) Pure pristine cotton fabric coated with Teflon; (b) Cotton fabric decorated with a secondary micro-sized layer of $\mathrm{ZnO}$ microparticles followed by Teflon coating; (c) Cotton fabric decorated with a secondary nano-sized layer of $\mathrm{ZnO}$ nanowires followed by Teflon coating; (d) Cotton fabric decorated with hierarchical tri-layers composed of the $\mathrm{ZnO}$ nanoflower-over-nanowire structures followed by Teflon coating. The scale bar in each image in the first column (i) indicates $30 \mu \mathrm{m}$; while those in the second (ii) and third (iii) columns indicate $1 \mu \mathrm{m}$.

\subsection{Surface Wettability of Treated Cotton Fabrics}

The Teflon-coated cotton fabrics decorated with the different surface morphologies of the $\mathrm{ZnO}$ structures allow the surfaces to exhibit different surface wettabilities. The surface wettabilities of the treated cotton fabrics were evaluated through the measurement of SCA, ACA, RCA, CAH, and SA, as shown in Figure 4. The results are summarized in Table 1, where the average values were used based on five parallel measurements. The results show that the CA of a water droplet on the hydrophobized cotton fabric increases gradually with the increase of the surface roughness provided by the decoration of $\mathrm{ZnO}$ structures, whereas the $\mathrm{CAH}$ and the SA decrease with the increase of the surface roughness. In the estimation of the $\mathrm{CAH}$, the ACA did not change much regardless of the surface roughness, whereas 
the RCA changed significantly with the increase of the surface roughness and mainly affected the CAH. The results indicate that the surface becomes more slippery (or less frictional) with the increase of the surface roughness. It is attributed to the fact that more air is entrained between the hydrophobic rough structures and the water drop has less contact with the solid surface with the increase of the surface roughness, following the Cassie-Baxter superhydrophobic wetting state [30], as depicted in Figure 5.
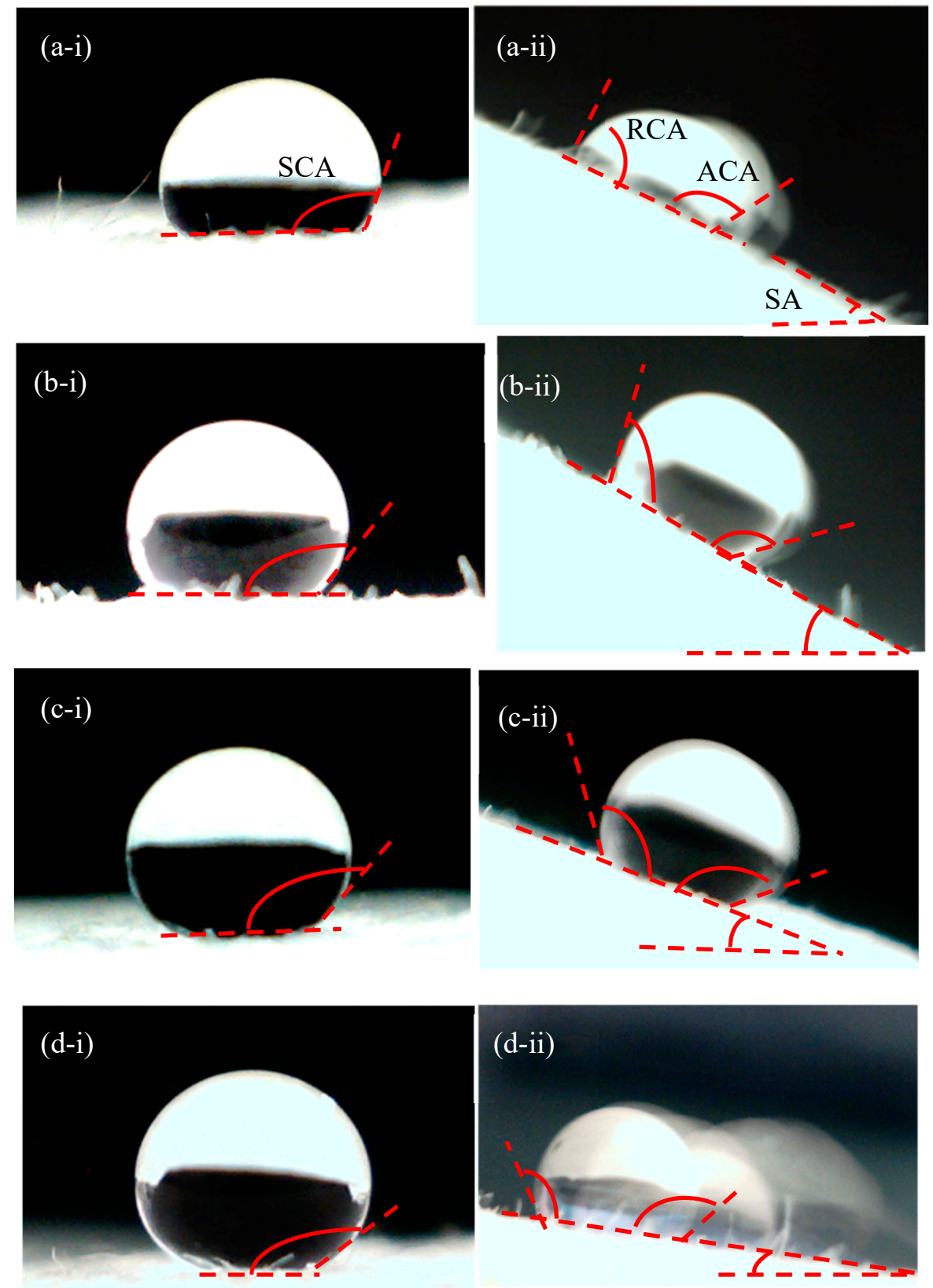

Figure 4. Surface wettability of treated cotton fabrics. (a) Pure pristine cotton fabric coated with Teflon; (b) Cotton fabric decorated with a secondary micro-sized layer of $\mathrm{ZnO}$ microparticles followed by Teflon coating; (c) Cotton fabric decorated with a secondary nano-sized layer of $\mathrm{ZnO}$ nanowires followed by Teflon coating; (d) Cotton fabric decorated with hierarchical tri-layers composed of the $\mathrm{ZnO}$ nanoflower-over-nanowire structures followed by Teflon coating. The first column (i) shows the static contact angle (SCA) of a water droplet; The second column (ii) shows the sliding angle (SA) and the advancing contact angle (ACA) and the receding contact angle (RCA) at the sliding. 
(a)

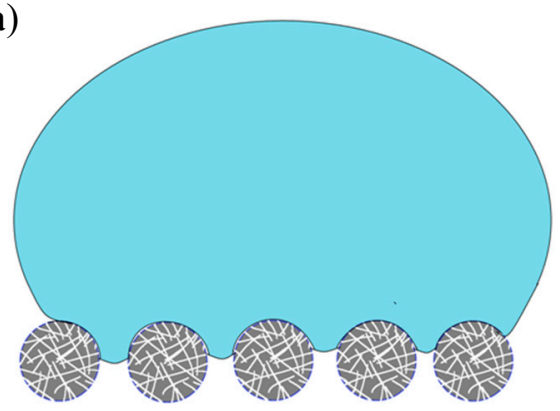

(c)

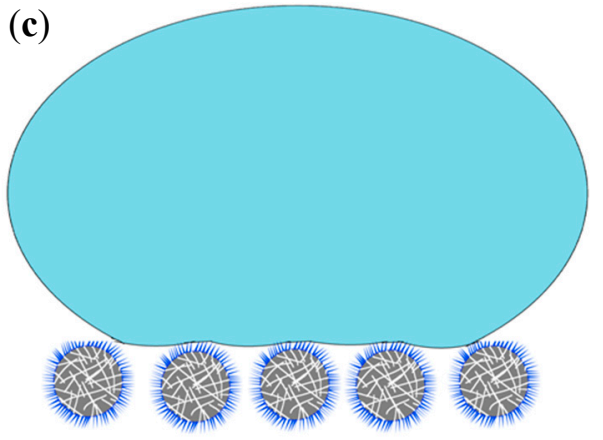

(b)

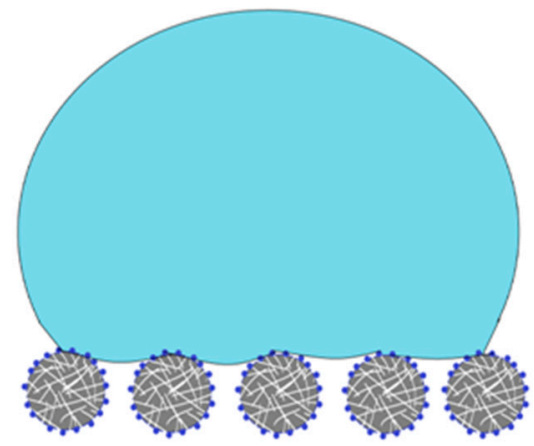

(d)

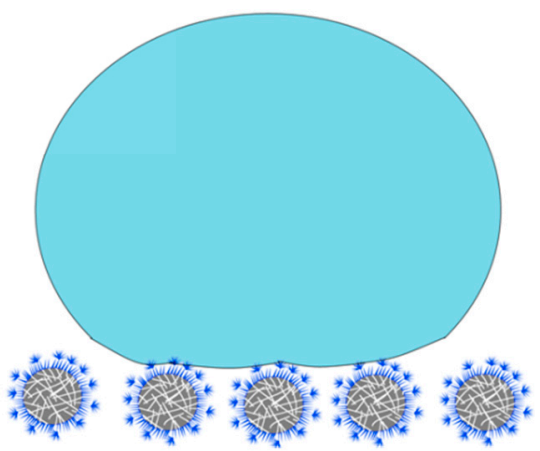

Figure 5. Schematics of the wetting states of water droplets on treated cotton fabrics. (a) Pure pristine cotton fabric coated with Teflon; (b) Cotton fabric decorated with a secondary micro-sized layer of $\mathrm{ZnO}$ microparticles followed by Teflon coating; (c) Cotton fabric decorated with a secondary nano-sized layer of $\mathrm{ZnO}$ nanowires followed by Teflon coating; (d) Cotton fabric decorated with hierarchical tri-layers composed of the $\mathrm{ZnO}$ nanoflower-over-nanowire structures followed by Teflon coating.

Table 1. Summary of the wettability of treated cotton fabrics.

\begin{tabular}{cccccc}
\hline Samples & SCA $\left({ }^{\circ}\right)$ & ACA $\left({ }^{\circ}\right)$ & RCA $\left({ }^{\circ}\right)$ & CAH $\left({ }^{\circ}\right)$ & SA $\left(^{\circ}\right)$ \\
\hline$(a)$ & 137 & 142 & 98 & 44 & 36 \\
$(b)$ & 143 & 148 & 113 & 35 & 27 \\
$(\mathrm{c})$ & 151 & 156 & 138 & 18 & 22 \\
$(\mathrm{~d})$ & 153 & 162 & 149 & 13 & 9 \\
\hline
\end{tabular}

\subsection{Anti-Icing and De-Icing Testing under Static Condition}

Figure 6 presents the anti-icing and de-icing behaviors of the superhydrophobic cotton fabrics measured in a static condition. The initial water droplets $(\sim 0.1 \mathrm{~mL}$, column i in Figure 6$)$ were all frozen on the four different types of the surfaces with not significant difference in the freezing time. When these cotton fabrics together with the frozen ice-beads forming on the surfaces were exposed to a room condition $\left(25^{\circ} \mathrm{C}\right.$ and $50 \% \mathrm{RH}$ ) on the $45^{\circ}$-slope plate (column ii in Figure 6), the ice beads on all of the fabric surfaces did not slide off the surfaces but initially stuck to the fabrics. After $5 \mathrm{~s}$ (column iii in Figure 6), the ice beads started to melt on the surface. Whereas all the ice beads formed on the pure Teflon-coated pristine cotton fabric (Figure 6(a-iii)), the Teflon-coated cotton fabric decorated with a secondary $\mathrm{ZnO}$ microstructures (Figure 6(b-iii)), and the Teflon-coated cotton fabric decorated with a secondary $\mathrm{ZnO}$ nanostructures (Figure 6(c-iii)) remained on the surfaces with melting, some ice bead formed on the Teflon-coated cotton fabric decorated with hierarchical tri-layers composed of the $\mathrm{ZnO}$ nanoflower-over-nanowire structures (Figure 6(d-iii)) started to slide off the surface. After $15 \mathrm{~s}$ (column iv in Figure 6), some ice beads on the Teflon-coated pristine cotton fabric (Figure 6(a-iv)) started to slide off the surface, whereas others remained on the surface. In the case of the Teflon-coated cotton fabric decorated with a secondary $\mathrm{ZnO}$ microstructures (Figure 6(b-iv)), the similar behaviors were shown except that there were some wetting spots left on the surface after the 
sliding-off. The secondary microstructures $(1-2 \mu \mathrm{m}$ in size) sparsely and randomly distributed over the cotton fibers allowed water to penetrate into the microstructures under the cold conditions, resulting in the local Wenzel state on the layer of secondary microstructures [41] and making the droplets subject to the rose-petal effect [42] with the increase of the pinning and adhesion force. In the cases of the Teflon-coated cotton fabrics decorated with the secondary $\mathrm{ZnO}$ nanostructures (Figure 6(c-iv)) and the hierarchical tri-layers composed of the $\mathrm{ZnO}$ nanoflower-over-nanowire structures (Figure 6(d-iv)), all the ice beads slid off the surfaces. Whereas many small wetting spots were left on the Teflon-coated cotton fabrics decorated with the secondary $\mathrm{ZnO}$ nanostructures (Figure 6(c-iv)) after the sliding-off, there were few on the Teflon-coated cotton fabrics decorated with the hierarchical tri-layers composed of the $\mathrm{ZnO}$ nanoflower-over-nanowire structures (Figure 6(d-iv)). Figure $6 \mathrm{~b}, \mathrm{c}$ imply that micro- and nanostructures larger than $\sim 200 \mathrm{~nm}$ cannot avoid water penetration into structures under the cold conditions. According to the classical nucleation theory, the radius of the critical nucleus is as small as $22 \mathrm{~nm}$ at $\sim-20^{\circ} \mathrm{C}$ [11], which is much smaller than the characteristic size of the nano-wires of the surface $(\sim 200 \mathrm{~nm})$ shown in Figure 3c. During the freezing process, the formation of ice nucleus within the nanowires is still energetically favorable and the Wenzel state cannot be avoided. However, on the surface with hierarchical morphologies shown in Figure 3d, the nanoflower over nanowires are smaller than the nanowires (only tens of nanometers). Thus, ice cannot easily form within the nanostructures and the Cassie-Baxter state maintains even the temperature decrease to as low as $-18^{\circ} \mathrm{C}$. The results demonstrate that although ice can still form and stick to the superhydrophobic fabrics with micro-sized structures under the static condition, the superhydrophobic fabric surface with nano-sized structures, especially the one with hierarchical morphologies, can show both superhydrophobicity with high CA, low $\mathrm{CAH}$, and a low $\mathrm{SA}$, and the efficient de-icing properties.

\subsection{Anti-Icing and De-Icing Testing under Dynamic Condition}

Figure 7 shows the results of anti-icing and de-icing behaviors measured in a dynamic condition with the spray test as illustrated in Figure 2. When a supercooled water droplet impacts on a surface, it instantaneously freezes along with a recalescent stage. Due to the release of latent heat of the flash freezing, only $\sim 20 \%$ of the liquid droplet freezes into ice and the rest turns to ice-water mixture with a jump of the temperature to $0{ }^{\circ} \mathrm{C}$ [29]. More importantly, evaporation and the resulting condensation occur during the freezing of the supercooled water. The first column (i) of Figure 7 shows that ice formed and accumulated on the surfaces after spraying the supercooled water $(50 \mathrm{~mL})$ on the cotton fabric samples tilted at $45^{\circ}$. The second and the third columns (ii and iii, respectively) of Figure 7 show the water remaining on the surfaces after being exposed to a room condition $\left(25{ }^{\circ} \mathrm{C}\right.$ and $50 \%$ $\mathrm{RH})$ with a gradual melting for 5 and $10 \mathrm{~s}$, respectively. On the pure Teflon-coated pristine cotton fabric (Figure 7a), the water droplet with a small size was melted and slid off the surface first, whereas that with a large size still remained on the surface even after $10 \mathrm{~s}$. Similar behaviors were shown on the Teflon-coated cotton fabric decorated with a secondary micro-sized layer of $\mathrm{ZnO}$ microparticles (Figure $7 \mathrm{~b}$ ). Since the tilted angle of the surface is $45^{\circ}$, larger than the sliding angle (SA) under the Cassie-Baxter state (Table 1), the contradiction clearly indicates that the Wenzel state exists during the freezing of the supercooled droplet. In the case of the Teflon-coated cotton fabric decorated with a secondary nano-sized layer of $\mathrm{ZnO}$ nanowires (Figure 7c), most of the water slid off the surface after $10 \mathrm{~s}$, although some of them remained on the surface only after $5 \mathrm{~s}$. In the case of the Teflon-coated cotton fabric decorated with hierarchical tri-layers composed of the $\mathrm{ZnO}$ nanoflower-over-nanowire structures (Figure 7d), most of the water slid off the surface after $5 \mathrm{~s}$, taking away the ice accumulated on the surface and leaving a clean surface. Even though the supercooled droplet freezes in an extremely fast speed as soon as it comes in contact with the surface, the intense evaporation of water vapor results in the formation of frost within the surface structures, which will affect the surface behavior. It has been demonstrated that microstructures cannot avoid frost formation due to vapor deposition [12]. This is in agreement with our experiments that the mobility of the frozen droplet decreased or disappeared on the microstructured superhydrophobic surfaces. On the nanostructured surfaces, especially the 
nanoflower-over-nanowire structures, ice nucleus can significantly be avoided within the structures due to the relative small size to that of ice nucleus. Therefore, the Cassie-Baxter state as well as the high mobility of the molten droplet are insured in our experiments. The results reveal that the nanostructures of the superhydrophobic cotton fabric can insure the superhydrophobicity and the effective anti/de-icing properties even after the fast freezing of a deeply cooled water droplet.

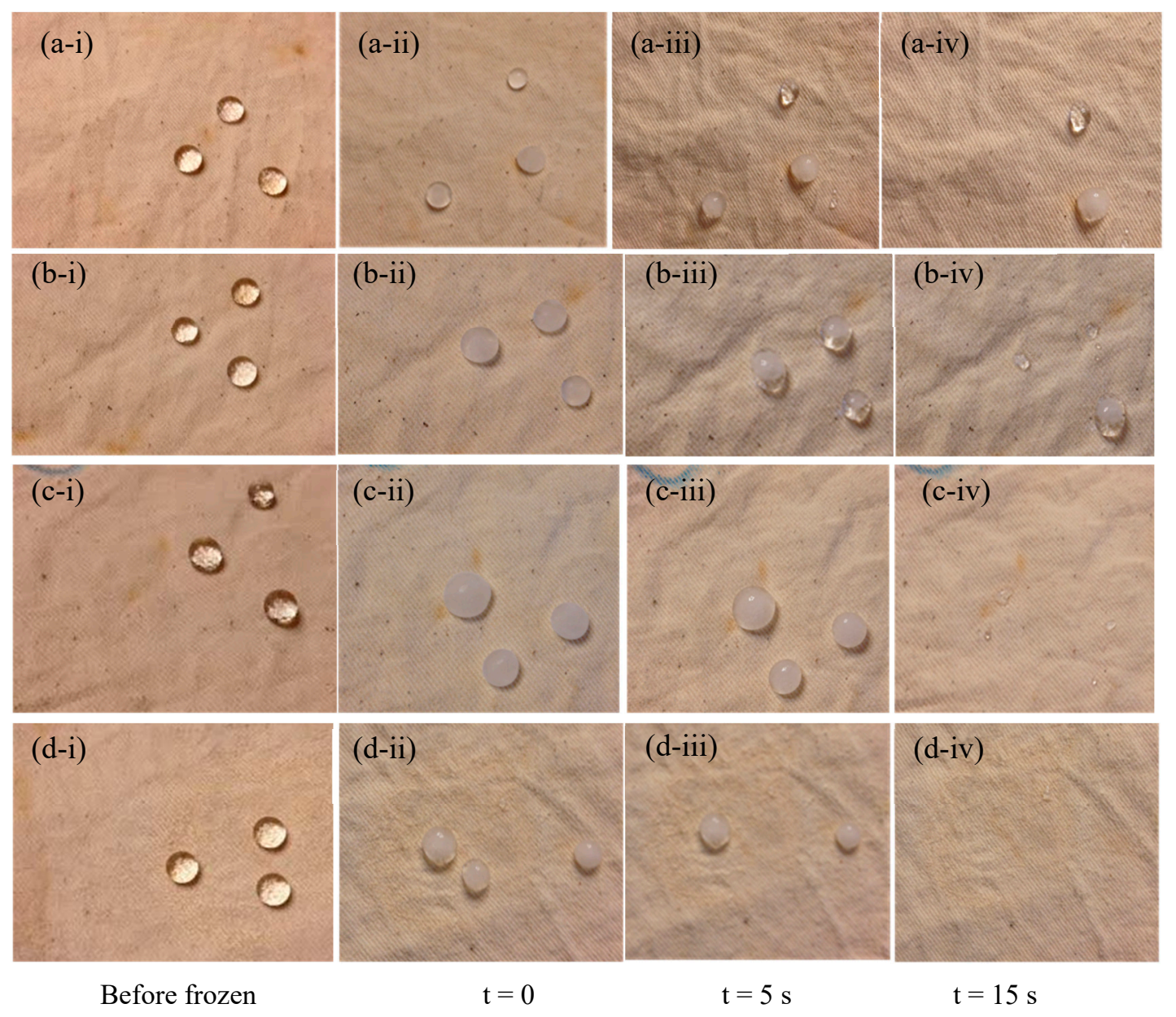

Figure 6. Anti-icing and de-icing behaviors measured in a static condition. (a) Pure pristine cotton fabric coated with Teflon; (b) Cotton fabric decorated with a secondary micro-sized layer of $\mathrm{ZnO}$ microparticles followed by Teflon coating; (c) Cotton fabric decorated with a secondary nano-sized layer of $\mathrm{ZnO}$ nanowires followed by Teflon coating; (d) Cotton fabric decorated with hierarchical tri-layers composed of the $\mathrm{ZnO}$ nanoflower-over-nanowire structures followed by Teflon coating. The first column (i) shows the initial water droplets placed on horizontally leveled surfaces before freezing; The second column (ii) shows the fully frozen water droplets on the leveled surfaces; The third column (iii) and the fourth column (iv) show the water droplets remaining on the surfaces after the surfaces were tilted at $45^{\circ}$ and exposed to a room condition $\left(25^{\circ} \mathrm{C}\right.$ and $\left.50 \% \mathrm{RH}\right)$ for 5 and $15 \mathrm{~s}$, respectively. 

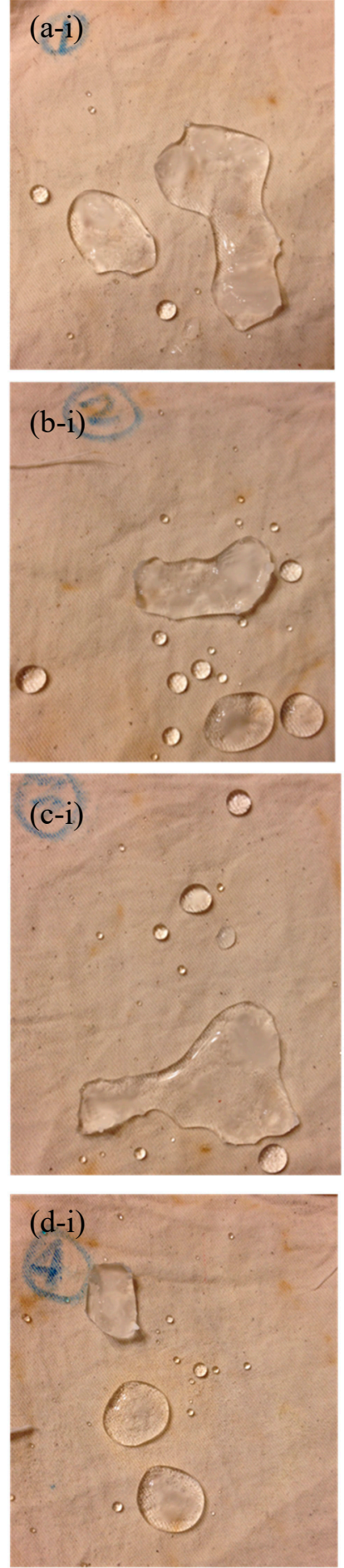

$\mathrm{t}=0 \mathrm{~s}$
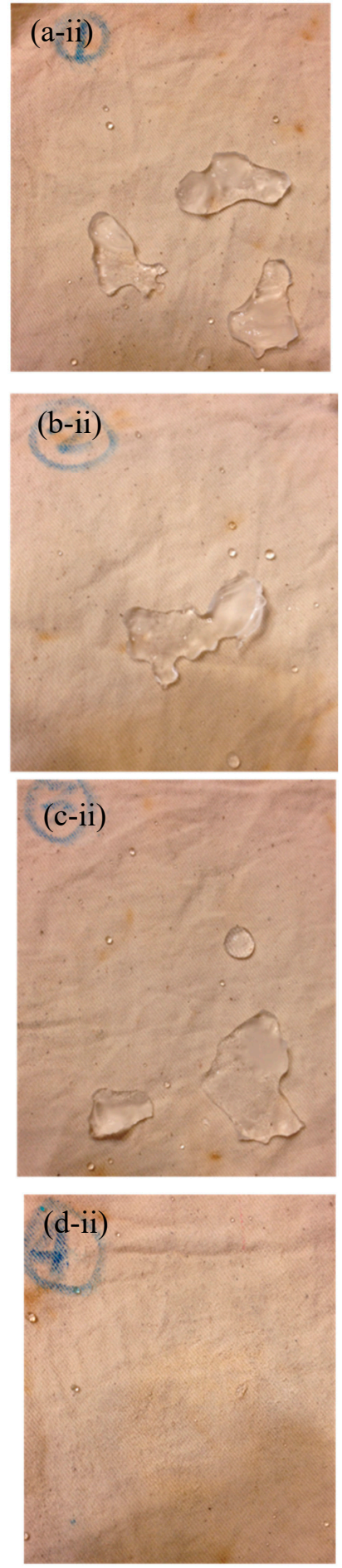

$\mathrm{t}=5 \mathrm{~s}$
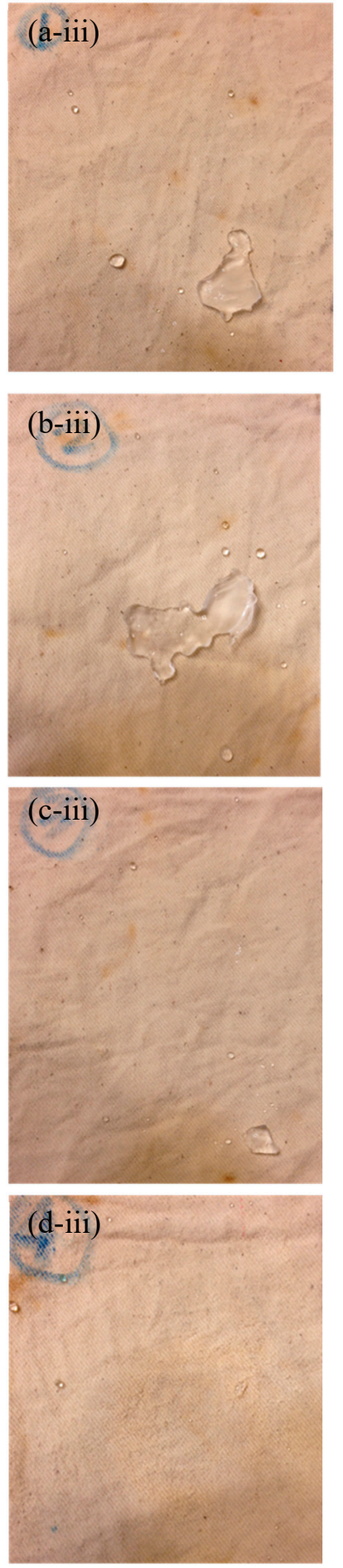

$\mathrm{t}=10 \mathrm{~s}$

Figure 7. Anti-icing and de-icing behaviors measured in a dynamic condition. (a) Pure pristine cotton fabric coated with Teflon; (b) Cotton fabric decorated with a secondary micro-sized layer of $\mathrm{ZnO}$ microparticles followed by Teflon coating; (c) Cotton fabric decorated with a secondary nano-sized layer of $\mathrm{ZnO}$ nanowires followed by Teflon coating; (d) Cotton fabric decorated with hierarchical tri-layers composed of the $\mathrm{ZnO}$ nanoflower-over-nanowire structures followed by Teflon coating. The first column (i) shows the initial water left on the $45^{\circ}$-tilted surfaces after spraying 50 -mL supercooled water; The second column (ii) and the third column (iii) show the water remaining on the surfaces after the surfaces were further exposed to a room condition $\left(25^{\circ} \mathrm{C}\right.$ and $\left.50 \% \mathrm{RH}\right)$ for 5 and $10 \mathrm{~s}$, respectively. The initial water volume is $50 \mathrm{~mL}$. 


\section{Conclusions}

The anti-icing and de-icing properties of superhydrophobic cotton fabrics with different surface morphologies were examined under both static (sessile droplet) and dynamic (spraying) conditions. The fabric with a higher contact angle and a lower sliding angle or lower contact angle hysteresis to liquid water exhibited more effective anti-icing and de-icing properties. While the anti-icing effects (e.g., delay of ice formation and less amount of ice accretion) were primarily shown in the dynamically loaded condition (spraying), a similar de-icing capability was shown in both the statically loaded and the dynamically impinged water droplets. The significance of this work is that the anti-icing and the de-icing behaviors of superhydrophobic fabrics were studied for the first time, demonstrating that nanostructured superhydrophobic fabrics also have great potential for the anti- and de-icing surfaces. In comparison with conventional superhydrophobic surfaces made on hard substrates, the soft and flexible superhydrophobic fabrics are porous and air-permeable materials that can provide and sustain air between water/fabric interfaces more effectively, which may lead to broader applicability of textile-based materials for the design and fabrication of anti- and de-icing materials.

Author Contributions: Supervision, C.-H.C.; Conceptualization, Y.L. and C.-H.C.; Methodology, validation, and investigation, Y.L.; Date analysis, Y.L. and D.S.; Writing, Y.L., D.S., and C.-H.C.

Funding: This work was funded by National Science Foundation, Division of Civil, Mechanical and Manufacturing Innovation (1537474).

Conflicts of Interest: The authors declare no conflict of interest.

\section{References}

1. Nakajima, A.; Hashimoto, K.; Watanabe, T. Recent Studies on Super-Hydrophobic Films. Monatsh. Chem. 2001, 132, 31-41. [CrossRef]

2. Lafuma, A.; Quere, D. Superhydrophobic States. Nat. Mater. 2003, 2, 457-460. [CrossRef] [PubMed]

3. Roach, P.; Shirtcliffe, N.J.; Newton, M.I. Progress in Superhydrophobic Surface Development. Soft Matter 2008, 4, 224-240. [CrossRef]

4. Bocquet, L.; Lauga, E. A Smooth Future? Nat. Mater. 2011, 10, 334-337. [CrossRef] [PubMed]

5. Blossey, R. Self-Cleaning Surfaces-Virtual Realities. Nat. Mater. 2003, 2, 301-306. [CrossRef] [PubMed]

6. Fürstner, R.; Barthlott, W.; Neinhuis, C.; Walzel, P. Wetting and Self-Cleaning Properties of Artificial Superhydrophobic Surfaces. Langmuir 2005, 21, 956-961. [CrossRef] [PubMed]

7. Liu, Y.; Xin, J.H.; Choi, C.-H. Cotton Fabrics with Single-Faced Superhydrophobicity. Langmuir 2012, 28, 17426-17434. [CrossRef] [PubMed]

8. Lee, C.; Choi, C.-H.; Kim, C.-J. Superhydrophobic Drag Reduction in Laminar Flows: A Critical Review. Exp. Fluids 2016, 57, 176. [CrossRef]

9. Aljallis, E.; Sarshar, M.A.; Datla, R.; Sikka, V.; Jones, A.; Choi, C.-H. Experimental Study of Skin Friction Drag Reduction on Superhydrophobic Flat Plates in High Reynolds Number Boundary Layer Flow. Phys. Fluids 2013, 25, 025103. [CrossRef]

10. Song, D.; Song, B.; Hu, H.; Du, X.; Du, P.; Choi, C.-H.; Rothstein, J.P. Effect of a Surface Tension Gradient on the Slip Flow along a Superhydrophobic Air-Water Interface. Phys. Rev. Fluids 2018, 3, 033303. [CrossRef]

11. Gao, L.; Jones, A.K.; Sikka, V.K.; Wu, J.; Gao, D. Anti-Icing Superhydrophobic Coatings. Langmuir 2009, 25, 12444-12448.

12. Kripa, K.V.; Tao, D.; Smith, J.D.; Ming, H.; Nitin, B. Frost Formation and Ice Adhesion on Superhydrophobic Surfaces. Appl. Phys. Lett. 2010, 97, 234102. [CrossRef]

13. Mishchenko, L.; Hatton, B.; Bahadur, V.; Taylor, J.A.; Krupenkin, T.; Aizenberg, J. Design of Ice-Free Nanostructured Surfaces Based on Repulsion of Impacting Water Droplets. ACS Nano 2010, 4, 7699-7707. [CrossRef] [PubMed]

14. Sarshar, M.A.; Swarctz, C.; Hunter, S.; Simpson, J.; Choi, C.H. Effects of Contact Angle Hysteresis on Ice Adhesion and Growth on Superhydrophobic Surfaces under Dynamic Flow Conditions. Colloid Polym. Sci. 2013, 291, 427-435. [CrossRef] 
15. Liu, K.; Zhang, M.; Zhai, J.; Wang, J.; Jiang, L. Bioinspired Construction of Mg-Li Alloys Surfaces with Stable Superhydrophobicity and Improved Corrosion Resistance. Appl. Phys. Lett. 2008, 92, 183103. [CrossRef]

16. Zhang, F.; Zhao, L.; Chen, H.; Xu, S.; Evans, D.G.; Duan, X. Corrosion Resistance of Superhydrophobic Layered Double Hydroxide Films on Aluminum. Angew. Chem. Int. Ed. 2008, 47, 2466-2469. [CrossRef] [PubMed]

17. Jeong, C.; Lee, J.; Sheppard, K.; Choi, C.-H. Air-Impregnated Nanoporous Anodic Aluminum Oxide Layers for Enhancing the Corrosion Resistance of Aluminum. Langmuir 2015, 31, 11040-11050. [CrossRef] [PubMed]

18. Lee, J.; Shin, S.; Jiang, Y.; Jeong, C.; Stone, H.A.; Choi, C.-H. Oil-Impregnated Nanoporous Oxide Layer for Corrosion Protection with Self-Healing. Adv. Funct. Mater. 2017, 27, 1606040. [CrossRef]

19. Ressine, A.; Marko-Varga, G.; Laurell, T.; El-Gewely, M.R. Porous Silicon Protein Microarray Technology and Ultra-/Superhydrophobic States for Improved Bioanalytical Readout. Biotechnol. Annu. Rev. 2007, 13, 149-200. [PubMed]

20. Choi, C.-H.; Kim, C.-J. Droplet Evaporation of Pure Water and Protein Solution on Nanostructured Superhydrophobic Surfaces of Varying Heights. Langmuir 2009, 25, 7561-7567. [CrossRef] [PubMed]

21. Hizal, F.; Rungraeng, N.; Lee, J.; Jun, S.; Busscher, H.J.; van der Mei, H.C.; Choi, C.-H. Nanoengineered Superhydrophobic Surfaces of Aluminum with Extremely Low Bacterial Adhesivity. ACS Appl. Mater. Int. 2017, 9, 12118-12129. [CrossRef] [PubMed]

22. Xu, W.; Choi, C.-H. Effects of Surface Topography and Colloid Particles on the Evaporation Kinetics of Sessile Droplets on Superhydrophobic Surfaces. J. Heat Transf. 2012, 134, 051022-051027. [CrossRef]

23. Miljkovic, N.; Enright, R.; Wang, E.N. Effect of Droplet Morphology on Growth Dynamics and Heat Transfer during Condensation on Superhydrophobic Nanostructured Surfaces. ACS Nano 2012, 6, 1776-1785. [CrossRef] [PubMed]

24. Liu, Y.; Choi, C.-H. Condensation-Induced Wetting State and Contact Angle Hysteresis on Superhydrophobic Lotus Leaves. Colloid Polym. Sci. 2013, 291, 437-445. [CrossRef]

25. Betz, A.R.; Jenkins, J.; Kim, C.J.; Attinger, D. Boiling Heat Transfer on Superhydrophilic, Superhydrophobic, and Superbiphilic Surfaces. Int. J. Heat Mass. Tranf. 2013, 57, 733-741. [CrossRef]

26. Xu, W.; Leeladhar, R.; Tsai, Y.-T.; Yang, E.-H.; Choi, C.-H. Evaporative Self-Assembly of Nanowires on Superhydrophobic Surfaces of Nanotip Latching Structures. Appl. Phys. Lett. 2011, 98, 073101. [CrossRef]

27. Lee, S.; Kim, W.; Yong, K. Overcoming the Water Vulnerability of Electronic Devices: A Highly Water-Resistant ZnO Nanodevice with Multifunctionality. Adv. Mater. 2011, 23, 4398-4402. [CrossRef] [PubMed]

28. De Angelis, F.; Gentile, F.; Mecarini, F.; Das, G.; Moretti, M.; Candeloro, P.; Coluccio, M.L.; Cojoc, G.; Accardo, A.; Liberale, C. Breaking the Diffusion Limit with Super-Hydrophobic Delivery of Molecules to Plasmonic Nanofocusing SERS Structures. Nat. Photon. 2011, 5, 682-687. [CrossRef]

29. Jung, S.; Tiwari, M.K.; Poulikakos, D. Frost Halos from Supercooled Water Droplets. Proc. Natl. Acad. Sci. USA 2012, 109, 16073-16078. [CrossRef] [PubMed]

30. Cassie, A.B.D.; Baxter, S. Wettability of Porous Surfaces. Trans. Faraday Soc. 1944, 40, 0546-0550. [CrossRef]

31. Vasileiou, T.; Gerber, J.; Prautzsch, J.; Schutzius, T.M.; Poulikakos, D. Superhydrophobicity Enhancement through Substrate Flexibility. Proc. Natl. Acad. Sci. USA 2016, 113, 13307-13312. [CrossRef] [PubMed]

32. Gilet, T.; Bourouiba, L. Fluid Fragmentation Shapes Rain-Induced Foliar Disease Transmission. J. R. Soc. Interface 2015, 12, 20141092. [CrossRef] [PubMed]

33. Ina, R.; James, W.; Reza, R.; Thomas, B.; Sachin, K.; Ramesh, J. Nanoindentation Measurements of Teflon-AF Nanosheets. J. Appl. Polym. Sci. 2015, 132, 41360.

34. Ramimoghadam, D.; Hussein, M.; Taufiq-Yap, H. The Effect of Sodium Dodecyl Sulfate (SDS) and Cetyltrimethylammonium Bromide (CTAB) on the Properties of ZnO Synthesized by Hydrothermal Method. Int. J. Mol. Sci. 2012, 13, 13275-13293. [CrossRef] [PubMed]

35. Kołodziejczak-Radzimska, A.; Jesionowski, T. Zinc Oxide-From Synthesis to Application: A Review. Materials 2014, 7, 2833-2881. [CrossRef] [PubMed]

36. Rahman, M.Y.A.; Umar, A.A.; Taslim, R.; Salleh, M.M. Effect of Surfactant on the Physical Properties of Zno Nanorods and the Performance of Zno Photoelectrochemical Cell. J. Exp. Nanosci. 2015, 10, 599-609. [CrossRef]

37. Usui, H. The Effect of Surfactants on the Morphology and Optical Properties of Precipitated Wurtzite ZnO. Mater. Lett. 2009, 63, 1489-1492. [CrossRef] 
38. Jin, C.; Li, J.; Han, S.; Wang, J.; Sun, Q. A Durable, Superhydrophobic, Superoleophobic and Corrosion-Resistant Coating with Rose-Like ZnO Nanoflowers on a Bamboo Surface. Appl. Surf. Sci. 2014, 320, 322-327. [CrossRef]

39. Wang, C.-F.; Tzeng, F.-S.; Chen, H.-G.; Chang, C.-J. Ultraviolet-Durable Superhydrophobic Zinc Oxide-Coated Mesh Films for Surface and Underwater-Oil Capture and Transportation. Langmuir 2012, 28, 10015-10019. [CrossRef] [PubMed]

40. Shaban, M.; Mohamed, F.; Abdallah, S. Production and Characterization of Superhydrophobic and Antibacterial Coated Fabrics utilizing ZnO Nanocatalyst. Sci. Rep. 2018, 8, 3925. [CrossRef] [PubMed]

41. Wenzel, R.N. Resistance of Solid Surfaces to Wetting by Water. Ind. Eng. Chem. 1936, 28, 988-994. [CrossRef]

42. Bhushan, B.; Nosonovsky, M. The Rose Petal Effect and the Modes of Superhydrophobicity. Philos. Trans. R. Soc. A 2010, 368, 4713-4728. [CrossRef] [PubMed]

(C) 2018 by the authors. Licensee MDPI, Basel, Switzerland. This article is an open access article distributed under the terms and conditions of the Creative Commons Attribution (CC BY) license (http://creativecommons.org/licenses/by/4.0/). 